\title{
A Comprehensive Study About The Predominance of Burnout Syndromes and Its Determinants Among Physicians in Bangkok.
}

\author{
${ }^{1}$ ShibuDharmarajan, ${ }^{2}$ PraditNgonmanee, ${ }^{3}$ XimanZong, ${ }^{4}$ JenetteBucog Villegas, ${ }^{5}$ ThidaratSukhindr, \\ ${ }^{6}$ Bhudnumphueng, ${ }^{7}$ Jasseer Jabbar \\ 1,2, 3,4, 5, ${ }^{\mathrm{M}}$ Martin de Tours School of Management and Economics \\ Assumption University of Thailand \\ dr.manasasthri@gmail.com,praditngn@gmail.com, auximan@yahoo.com, jvillegas@au.edu, \\ Thidarat.skh@gmail.com, aj.np@ hotmail.com \\ ${ }^{7}$ Department of Psychology,University of Kerala, India. \\ drjasseer@yahoo.co.in
}

\begin{abstract}
Physicians, the health care practitioners are prone to develop burn out syndromes, as they are frequently overloaded with their routine health care practices of a wider range of physical and psychological health issues. The present investigation is employed to measure the predominance of burnout syndromes and its determinants of physicians working in Bangkok, the capital of Thailand. A self-administered translated (Thai) adaptation of Astudillo and Mendinueta questionnaire used to measure the burnout syndrome. In addition to that a personal data sheet also used to collect their socio-demographic data and job characteristics. The questionnaires distributed to the physicians from government and private hospitals in Bangkok. A total of 800 questionnaires was distributed and 737 physicians responded (Response rate $=92.1 \%$ ). The findings of the study revealed that, of the all, $28.2 \%$ of physicians were suffering from burnout syndromes. It is also noted that there was a statistically significant difference $(p<0.001)$ in burnout syndromes between female $(M=1.34 ; S D=0.47)$ and male $(M=1.31$; $S D=0.41)$. A statistically significant difference $(p<0.001)$ was also obtained in association between burnout syndromes and the physicians'departments of working. Physicians were working in surgical department was found high in burnout syndromes $(M=1.38 ; S D=0.49)$ than the physicians in the medical department $(M=1.23 ; S D=$ 0.42 ). The burnout syndromes were not associated with age, place of work, marital status, and years of expe rience. Irritability and painful symptoms were the most common symptoms found in the physicians.
\end{abstract}

Key words: Predominance, Burnout syndrome, Physicians, irritability, painful symptoms

\section{Introduction}

Since physicians are continually exposed to human sufferings they have a greater risk of stress related problems like burnout. It is a fact that the physicians are health care practitioners involving with a broad range of illness (both physical and psychological) of every person seeking medical care. When they involve selflessly, stress may arise from their work, contacts with the demands of the hospitals they work, etc. Because their primary duties are, to diagnose, prescribe medicines or arrange treatments, and promote the patients physical and mental health. In addition to these, they arrange other health care professionals to support the patients, irrespective of culture, race, caste or social status in emergency situations. Dealing with the suffering patients is unavoidable in the medical profession, so some kind of emotional and physical stress is common in physicians when they immerse in their duties. This extremely busy schedule might push them at the risk of burnout.

Still, it is controversial in defining burnout. So far the stress researchers couldn't give a proper definition of burnout. Generally speaking, it is a disease of the modern society (Abdulla et.al. 2011). The modern psychologists tried to refers burnout, a state of physical, emotional and mental exhaustion caused by long term involvement in emotionally demanding situations which is associated with the individuals who work with people. When burnout occurs, affected individuals essentially lose their spirit they become emotionally drained, they feel used up, and they lose their sense of personal accomplishment. In another way the psychologist defines burn out is a psychological reaction to chronic emotional stress accompanied by depersonalization, and reduced personal accomplishment. In the view of Yousefy\&Ghassemi (2006), it is the reaction to the chronic emotional stress due to the continuous interaction with high demanding people, when they have issues or need assistance. Especially people living in distressing situations can push them into extreme pressure and when then have no escape from this condition; they may feel exhausted, empty, or burnout. Stress from working conditions can also 
lead to physical or mental exhaustion. Due to extreme commitment of the individuals they neglect their own needs may also be at the root of the psychological reaction, especially the emotional exhaustion. But some psychologists argue that, exhaustion is not a sign of disease, but it is a normal reaction to stress. Anyhow, from the modern stress researchers' point of view burnout is not simple, but it has a wider

From the academicians and stress researchers' point of view, burnout is considered to have a range of symptoms. But these symptoms vary from person to person. In some people it can be seen as physical overwhelming or exhausted, But in some others it is accompanied by intense feelings and negative emotions that trigger to fight-flight responses to keep the body in a continual state of heightened physiological arousal and cause most of psychosomatic symptoms such as sleep problems, stomach disorders, headache, muscle pain etc. (Melamed et al., 2006) But all definitions given so far have some common symptoms and those are regarded as being the consequence of stressful activities in or outside the job (Farber, 1998). In that regards caring family members could also be the possible sources of stress outside job.

Over the past few decades of intensive researches, the stress researchers' highlighted three main areas of symptoms are considered to be signs of burnout syndrome. The signs of the burnout syndrome are

- Emotional exhaustion: It is a chronic state of physical and emotional diminution due to excess work load or personal demands and continuous work. It's a state of feeling of being emotionally strain and exhausted one's work.

- Depersonalization: It is an alienation from job or job related activities such as perceived negative and frustrating type of attitude towards work, and carry negative or derisive attitude towards their work environment and their colleagues. Concurrently, that increases a psychological distance, and which disengages themselves from their work.

- Reduced personal accomplishment: Burnout mainly affects the persons whole spears of every day task including, work, home, and or even caring for family members. People with burnout gaze their activities very negatively, and they find it hard to concentrate, are dispirited and experience a lack of creativity. Moreover it refers to negative evaluations of oneself.

In summary, burnout is a state of emotional, mental, and physical exhaustion caused by excessive and prolonged stress. It is not only changing the emotions but it also reduces productivity and saps the individual's energy as well, and eventually the individual feels like she/he/ has nothing to give. However, burnout still may be a greater problem in occupations where employees are more in interaction with other people (clients, customers, etc.) rather than dealing with things and information (Maslach et. al., 2001).

Further, Burisch (2006) highlighted that the basic facets of the burnout process can be summed up by high work load, such as excess job demands, high expectations on one's job performed and which may increase the perceived level of job stress and the resultant effect is emotional exhaustion, depersonalization, and reduced accomplishments.

The physicians are life recovers. Though it is a fact, sometimes the repeated failures after the excessive effort to a life project denote the inefficiency of the physicians and which may cause frustration or fatigue. This may create a kind of lost feeling or stressful working conditions in medical profession (Spickard, et.al. 2002). Another reason is considered as the cause of stress is the situations in which the patient care and job dissatisfaction in the medical profession. The situations like patients' cooperation, their recovery or death, the medical conditions and administrative decisions, lack of social support, conflict with peers and superiors, and the organizational structure increases the tension of the medical professionals and the result of these are excess stress. (Hamad Medical Corporation, 2009).

Many medical professionals reported that burnout has been associated with impaired job performance and poor health including headaches, sleeps disturbances, irritability, marital difficulties, fatigue, hypertension, anxiety, depression, myocardial infarction, alcoholism, and drug dependency. It isreciprocally affects the quality of health care provided to patients and this can lead to physician faults, and which can also be contributed to burnout as well.

Bangkok is the capital of Thailand has a rich historical and cultural background. As per the 2010 census the reckoned population of Bangkok is over 8.2 million. The system of healthcare in Bangkok is generally good. The healthcare services are provided through government and private hospitals. As per the report from the Ministry of Public health in 2010, 1002 public hospitals and 316 private hospitals are registered with the Ministry of Public Health. At present in Bangkok only 17, 164 physicians are working in various hospitals of 
Thailand (The Nation, 2013). This is insufficient to meet the care of patients. Moreover, most of the physicians in Bangkok do not have one specific place to work. Thai doctors (surgeons and physicians) have different working schedules at different hospitals that can be spread over the whole of Bangkok. Therefore, physicians are likely to go from one hospital to another to do even their rounds. So they tend to work very long hours. This kind of tedious or routines of work creates a greater amount of workload and later that may lead to job stress. Prolonged experiences of these stresses limit their tolerance level and psychologically or physically they react to it. Furthermore, there is no authentic information on burnout syndromes among physicians were available in Thailand. This is inspired the researchers focus on a study in the area of burnout syndrome in Bangkok. In that sense, this study has some novelty and is able to throw some lights in the areas of stress or burnout research. Hence the present study is tailored to measure the predominance of burnout syndromes and its determinants among physicians in Bangkok.

\section{Review of Literature}

To get legitimacy for the present investigation, the investigators reviewed some of the previous studies of burnout researches among medical professionals. The following are the available studies that tailored to get an overall idea about burnout on medical professionals. It is observed a prevalence of burnout syndrome in clinical nurses was explored by Ribeiro et.al. (2014), which showed that the percentage of burnout syndromes were higher $(10.1 \%)$ and $55.4 \%$ of subjects had a tendency to develop the burnout syndrome. In a nurses' sample, the socio demographic analysis claimed that most of them were married and childless women over 35 years of age. Their nature of work was the day shift for 36 hours weekly on average. The other background in formations regarding education and experience, the nurses had 2-6 years of post-graduation experience, and without extra employments. This study evidenced that the factors such as marital status, workload, emotion and work related stress aggravated the onset of the syndrome. The study concluded that the prevalence and propensity of burnout syndromes were high among nurses.

Verdugo et. al. (2013) conducted a study to understand the prevalence of burnout syndrome of nurses working in a Columbian hospital. They compared 32 nurses working in the inpatient services of the institution with 22 health professionals. This study concluded the fact that the health professionals were high in depersonalization and therefore they were vulnerable to suffer burnout. It is also noted that the gender, age, marital status, economic status, etc. not significant with burnout syndrome in professionals and hospital nursing. In a comparative study on burnout and satisfaction with work-life balance between US physicians and to the other workers in the US, Shanafelt and associates (2012), found out that burnout is more common among physicians than among other US workers. It is also noted that physicians in specialties at the front line of health care access to be at greater risk.

Costa, Samntos, and Andradein (2012) examined the burnout syndromes and associated factors among medical students were reported that the medical students were burned out. In Malawi referral hospital, the crosssectional study of Thorsen, Tharp, and Meguid in 2011revealed that high rate of burnout among maternal health staff was existed. This study paved the way to begin covering some gaps in the burnout research. They also reported that burnout is an important barometer of major dysfunctions in the workplace. Therefore, burnout may have serious implications not only for the quality of emotional, technical, and emergency obstetric care given to women, but also for the health and wellbeing of the maternal healthcare workers themselves.

A study related to the doctors' stress at work and burnout syndromes by Selmanovic and his associates (2011), noticed that the doctors in their workplace suffer from too many stresses. Further, they reported that lack of or insufficient coping with the chronic work stress led them to burn out. Most of the doctors couldn't find time to relax from their busy schedules and professional duties.

Abdulghafour, Bo-Harma, and Al-Randi (2011), in their research showed that physicians working in primary health care centers in Kuwait revealed the relationship between the degree of burnout problem among primary care physicians and social-demographic factors affecting its occurrence. A specially designed questionnaire used to measure emotional exhaustion, depersonalization, personal accomplishment, and involvement. The results highlighted that the four domains were associated with some of the studied sociodemographic variables and the job characteristics of the targeted physicians.

A study on burnout syndrome among ICU physicians by Sobrinholand et.al. (2009) concluded that an elevated prevalence of burnout syndrome among on-call physicians existed. Further, they reported that primarily those 
who described their work as inflicting many challenges to highly demanding situations. After all, an ICU is entirely different from other medical environment and moreover, in ICU the physicians are constantly open to stressful factors. Above all, ICU is primarily related to the fact that they care for patients at risk of imminent death.

Embriacoand Papzian, et.al. (2007) reported that50\% of critical care physicians and one third of critical care nurses experienced severe burnout syndrome. A similar study conducted by Patrick et.al. (2006) showed that Victorian ANF nurse members exhibited higher personal accomplishment and lower depersonalization compared to medical and overall data. The study highlighted the need for health care management to recognize the importance of work pressure in particular, to understand the potential detrimental effect that having to work pressured or unexpected overtime has on staff.

On the basis of the available information, the investigators hope that, the studies summarized above will throw adequate light on the research problem selected for the present investigation.

\section{Methodology}

As it is an explanatory research, a survey was conducted by the researchers. The population was targeted by the physicians working mainly in medical and surgical department in various (government/private) hospitals in Bangkok. A purposive or judgmental sampling was used for the present study. The present investigation is employed to measure the predominance of burnout syndromes and its determinants of physicians working in Bangkok, the capital of Thailand. A self-administered translated (Thai) adaptation of Astudillo and Mendinueta questionnaire used to measure the burnout syndrome. In addition to that a personal data sheet also used to collect their socio-demographic data and job characteristics. The questionnaires distributed to the physicians from government and private hospitals in Bangkok. The test is found with a high reliability of 0.856 . The questionnaires were distributed to all physicians after establishing a rapport with them. The questionnaire was divided into two parts. The first part covered the socio-demographic characteristics of physicians' such as their age, gender, marital status, income, department of working, nature of hospitals, place of working, and years of experience. The second part covered the symptoms of burnout syndrome (19 items). The research assistants explained the relevance of this study and invited their whole hearted participation from the respondents. To answer each question, the participants are asked to prefer one option from the four alternative responses. These four responses constituted a gradual score that ranged from 0 to 3, in which "never" scored 0, "sometimes" 1 , "often" 2, and "always" 4 respectively. The assessment scores were computed as a summation of answers to all 19 items, with a total minimum score of 0 and a total maximum score of 57 . A time frame was given to the physicians to respond to the questionnaires such as. A total of 800 questionnaires is distributed to the physicians working in various hospitals in Bangkok and 737 physicians responded appropriately, which indicate a response rate of $92.1 \%$.

The data analyses were done using SPSS. The main analyses were followed such as descriptive statistics in the form of frequencies and percentages for the qualitative variables, and means and standard deviations for quantitative variables. Independent sample t-test, and One-way ANOVA, was done to test the tenability of the hypothesis.

\section{Result}

To find out the predominance of burnout among physicians a percentage analysis of burnout symptoms was done and the major symptoms are explained below.

Symptoms of burnout syndrome were assessed separately and the percentage of each symptom was calculated. The physicians scored more than 19 points from the 19 items, as regarded with the predominance of burnout syndrome. From the light of the result, it is viewed that $28.2 \%$ of physicians were burned out. Irritability symptoms are observed more in physicians in the present study. Out of these 737 participants, 557 (75.6\%) of physicians experiences irritability sometimes. Regarding the other symptoms, $445(60.4 \%)$ of physicians were experiencing painful symptoms.

Self-criticism was noted in $424(57.5 \%)$, and consume analgesics were found in $408(55.4 \%)$ doctors respectively. Some of them are reported poor concentration and performance $(391=53.1 \%)$ that affect them when they feel burnout. Lack of organization $(382=51.8 \%)$, and Lack of sense of priority $(369=50.1 \%)$ were found the other symptoms they experience sometimes. 
From the Table 1, it is also noticeable that 320 (43.4\%) of doctors often experiences fatigue and $292(39.6 \%)$ doctors often experiences. Hence, it is from the light of the above results it is evident that burnout is not negligible and it is sometimes or often creating problems to the doctors.

Table 1: Percentage of symptoms of burnout syndrome among physicians

\begin{tabular}{|c|c|c|c|c|}
\hline Symptoms & $\begin{array}{l}\text { Never } \\
\text { n }(\%)\end{array}$ & $\begin{array}{l}\text { Sometimes } \\
\text { n }(\%)\end{array}$ & $\begin{array}{l}\text { Often } \\
\text { n (\%) }\end{array}$ & $\begin{array}{l}\text { Always } \\
\text { n (\%) }\end{array}$ \\
\hline Irritability & $80(10.9)$ & $557(75.6)$ & $75(10.2)$ & $25(3.4)$ \\
\hline Debility & $41(5.6)$ & $345(46.8)$ & $292(39.6)$ & $59(8.0)$ \\
\hline Self-criticism & $139(18.9)$ & $424(57.5)$ & $164(22.3)$ & $10(1.4)$ \\
\hline Insomnia & $119(16.1)$ & $405(55.0)$ & $179(24.3)$ & $34(4.6)$ \\
\hline Fatigue & $26(3.5)$ & $298(40.4)$ & $320(43.4)$ & $93(12.6)$ \\
\hline Spinal problem & $252(34.2)$ & $323(43.8)$ & $139(18.9)$ & $23(3.1)$ \\
\hline Lack of organization & $265(36.0)$ & $382(51.8)$ & $84(11.4)$ & $6(0.8)$ \\
\hline Lack of sense of priority & $292(39.6)$ & $369(50.1)$ & $67(9.1)$ & $9(1.2)$ \\
\hline Depressive states & $311(42.2)$ & $350(47.5)$ & $67(9.1)$ & $67(9.1)$ \\
\hline Feeling of failure & $390(52.9)$ & 277 (37.6) & $63(8.5)$ & $7(0.9)$ \\
\hline Painful symptoms & $117(15.9)$ & $445(60.4)$ & $145(19.7)$ & $145(19.7)$ \\
\hline Social isolation & $424(57.5)$ & $243(33.0)$ & $54(7.3)$ & $16(2.2)$ \\
\hline Poor concentration and performance & $288(39.1)$ & $391(53.1)$ & $50(6.8)$ & $8(1.1)$ \\
\hline Less caring attitude & $385(52.2)$ & $292(39.6)$ & $49(6.6)$ & $11(1.5)$ \\
\hline Problem with rest of team & $329(44.6)$ & $346(46.9)$ & $56(7.6)$ & $6(0.8)$ \\
\hline Dissatisfaction with work & $328(44.5)$ & $330(44.8)$ & $65(8.8)$ & $14(1.9)$ \\
\hline Change of profession & $460(62.4)$ & $235(31.9)$ & $39(5.3)$ & $3(0.4)$ \\
\hline Consume analgesics & $171(23.2)$ & $408(55.4)$ & $130(17.6)$ & $28(3.8)$ \\
\hline Consume sedatives & $535(72.6)$ & $183(24.8)$ & $17(2.3)$ & $2(0.3)$ \\
\hline
\end{tabular}

Table 2 presents the demographic characteristics of the physicians who participated in this study. Among the participants, 383 of them (52\%) were female, 270 (36.6\%) were belonged to 35-44yrs of age. Most of the physicians were married, $396(53.7 \%)$. More than $75 \%$ of physicians were working in urban areas, and most of them were employed in private hospitals. In department wise, most of them were working in the medical department, $490(66.5 \%)$ than in the surgical department. Most of the participants had more than five to ten years of experience, 261 (35.4\%) in their profession. 
Table II Demographic Characteristics of The Physicians

\begin{tabular}{|c|c|}
\hline 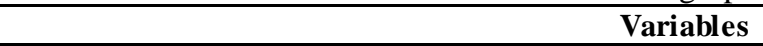 & n (\%) \\
\hline $\begin{array}{l}\text { Gender } \\
\text { Male } \\
\text { Female }\end{array}$ & $\begin{array}{l}354(48 \%) \\
383(52 \%)\end{array}$ \\
\hline $\begin{array}{l}\text { Age } \\
25-34 \text { yrs } \\
35-44 \text { yrs } \\
45 \text { yrs and above }\end{array}$ & $\begin{array}{l}261(35.4 \%) \\
270(36.6 \%) \\
206(28.0 \%)\end{array}$ \\
\hline $\begin{array}{l}\text { Marital status } \\
\text { Single } \\
\text { Married } \\
\text { Separated } \\
\text { Divorce } \\
\text { Widow/widower }\end{array}$ & $\begin{array}{l}326(44.2 \%) \\
396(53.7 \%) \\
10(1.4 \%) \\
02(0.3 \%) \\
03(0.4 \%)\end{array}$ \\
\hline $\begin{array}{l}\text { Place of work } \\
\text { Urban } \\
\text { Rural }\end{array}$ & $\begin{array}{l}556(76.8 \%) \\
171(23.1 \%)\end{array}$ \\
\hline $\begin{array}{l}\text { Nature of hospital } \\
\text { Government } \\
\text { Private }\end{array}$ & $\begin{array}{l}345(46.8 \%) \\
392(53.2 \%)\end{array}$ \\
\hline $\begin{array}{l}\text { Department } \\
\text { Medical } \\
\text { Surgical }\end{array}$ & $\begin{array}{l}490(66.5 \%) \\
247(36.5 \%)\end{array}$ \\
\hline $\begin{array}{l}\text { Years of experience } \\
\text { Less than } 5 \text { yrs } \\
5 \text { to } 10 \text { yrs } \\
11 \text { to } 15 \text { yrs } \\
16 \text { to } 20 \text { yrs } \\
\text { More than } 20 \text { yrs }\end{array}$ & $\begin{array}{l}137(18.6 \%) \\
261(35.4 \%) \\
116(15.7 \%) \\
107(14.5 \%) \\
116(15.7 \%)\end{array}$ \\
\hline
\end{tabular}

\section{Association between burnout syndrome and selected background characteristics}

The association between burnout syndrome and certain socio-demographic variables were computed and described below.

TableIII: Association between age and burnout syndrome

\begin{tabular}{|c|c|c|c|c|c|}
\hline \multicolumn{6}{|l|}{ ANOVA } \\
\hline \multicolumn{6}{|c|}{ Level of burnout syndrome } \\
\hline & Sum of Squares & df & Mean Square & $\mathrm{F}$ & Sig. \\
\hline Between Groups & .182 & 2 & .091 & .447 & .639 \\
\hline Within Groups & 149.115 & 734 & .203 & & \\
\hline Total & 149.297 & 736 & & & \\
\hline
\end{tabular}

It is evident from the Table 3 that the $\mathrm{F}$ value is not statistically significant. Hence it can be argued that burnout syndrome is independent of all age groups. In contrast, of the above result, a study conducted by Abdulla, L. et.al (2011) noted that, in terms of age and burnout, it had a significant relationship. In their study, they observed $41.2 \%$ of the general practitioners below 35 years of age and 22.2\% aged 35-44 years were burned out, and which shows younger healthcare physicians have high burnout syndrome than older healthcare physicians. However, in the present study irrespective of age all of the physicians were undergoing the burnout syndrome. 
Table IV: Association between gender and burnout syndrome

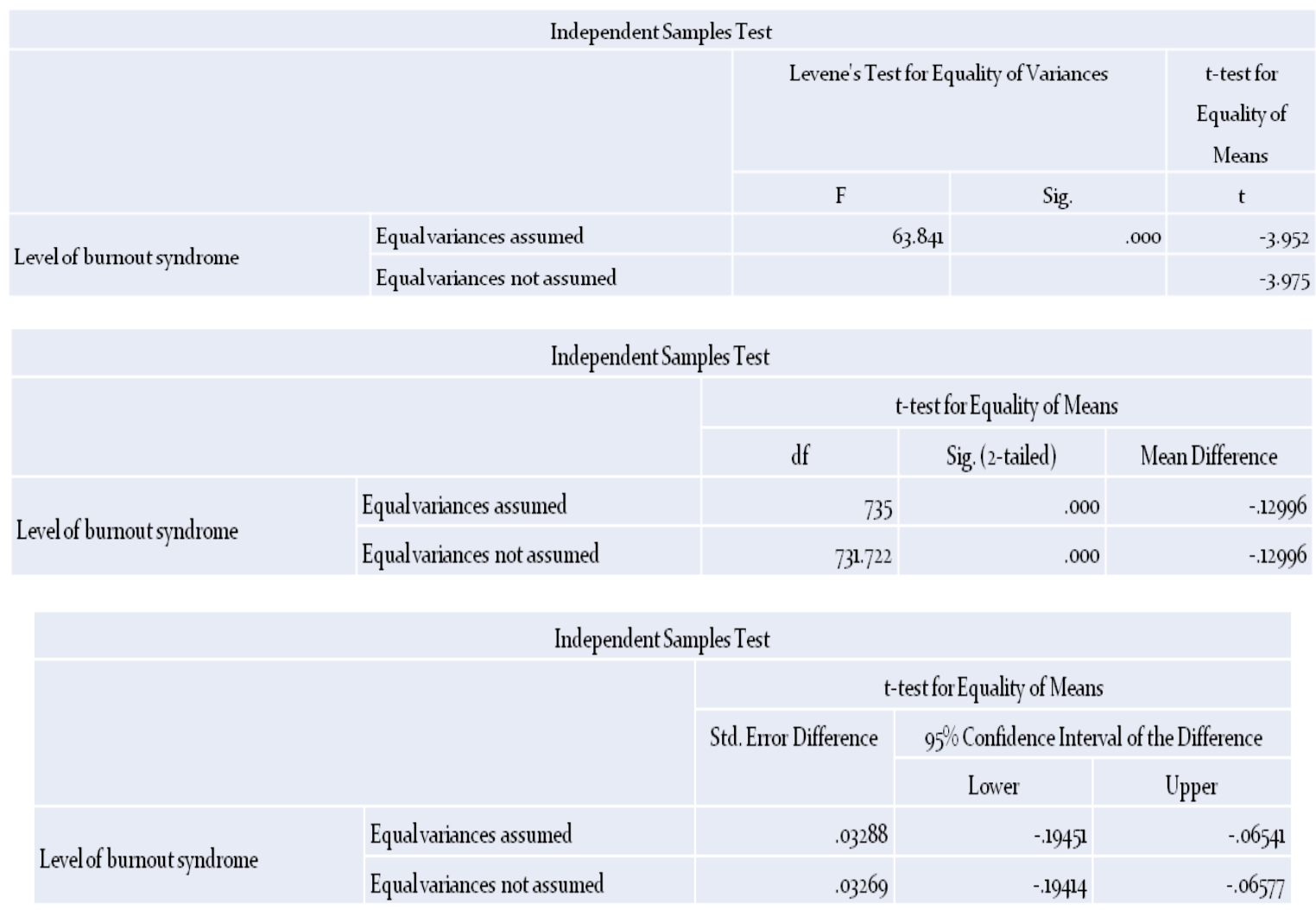

From the table 4 it is clearly seen that, there is a significant difference in the association between gender and burnout $(\mathrm{F}=63.84 ; \mathrm{p}=0.00)$.

Table V: Mean and standard deviation of gender and burnout syndrome Group Statistics

\begin{tabular}{|c|c|c|c|c|c|}
\hline & Gender & $\mathrm{N}$ & Mean & Std. Deviation & Std. Error Mean \\
\hline \multirow{2}{*}{ Level of burnout syndrome } & Male & 354 & 1.2147 & .41119 & .02185 \\
\hline & Female & 383 & 1.3446 & .47587 & .02432 \\
\hline
\end{tabular}

Based on the mean value (1.34) and standard deviation (0.47) it can be noted that burnout syndrome is higher among female physicians than male physicians $(\mathrm{M}=1.31)$ and $(\mathrm{SD}=0.41)$.

On the basis of the above result, it can be stated that female physicians experience more stress from their works and the prolonged experience of the stress may lead them to burn out. Whereas, male physicians may manage their stress because of that they found themselves as low in burnout. A similar result was obtained in the study by Abdulla, L et.al. (2011). In their study, they had a comparison between gender and the burnout syndrome among the general practitioners in Qatar was statistically significant. The findings of the study showed that female physicians were higher in burnout syndrome than male physicians.

Table VI: Association between Marital status and burnout syndrome

ANOVA

Level of burnout syndrome

\begin{tabular}{llllll} 
& Sum of Squares & df & Mean Square & F & Sig. \\
\hline Between Groups & 1.013 & 4 & .253 & 1.250 & .288 \\
\hline Within Groups & 148.284 & 732 & .203 & & \\
\hline Total & 149.297 & 736 & & &
\end{tabular}

In association between marital status and burnout syndrome, it can be noted that the p value is greater than 0.05 . On the basis of the result, it can be argued that marital statuses of the physicians are not having any significance with burnout syndrome and it is independent of marital status. 
Table VII: Association between place of work and burnout syndrome

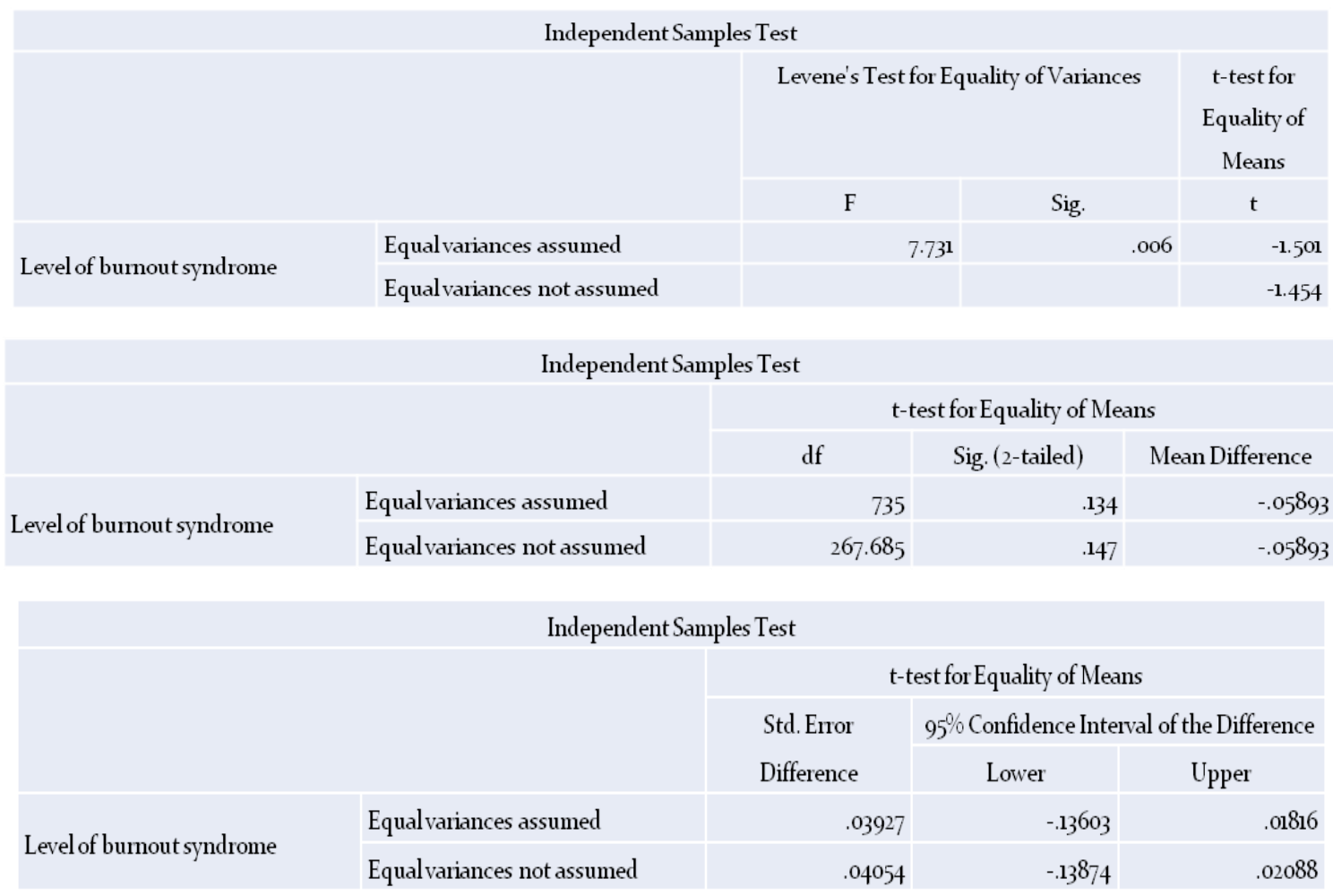

As is can see from the table ( $\mathrm{t}=-1.50$ and $\mathrm{p}=0.13$ ) which means that physicians' burnout syndrome has no connection with their place of work. Whether they work in urban/rural places they equally experience burnout.

Table VIII: Association between nature of hospital (Govt. /Pvt.) and burnout syndrome

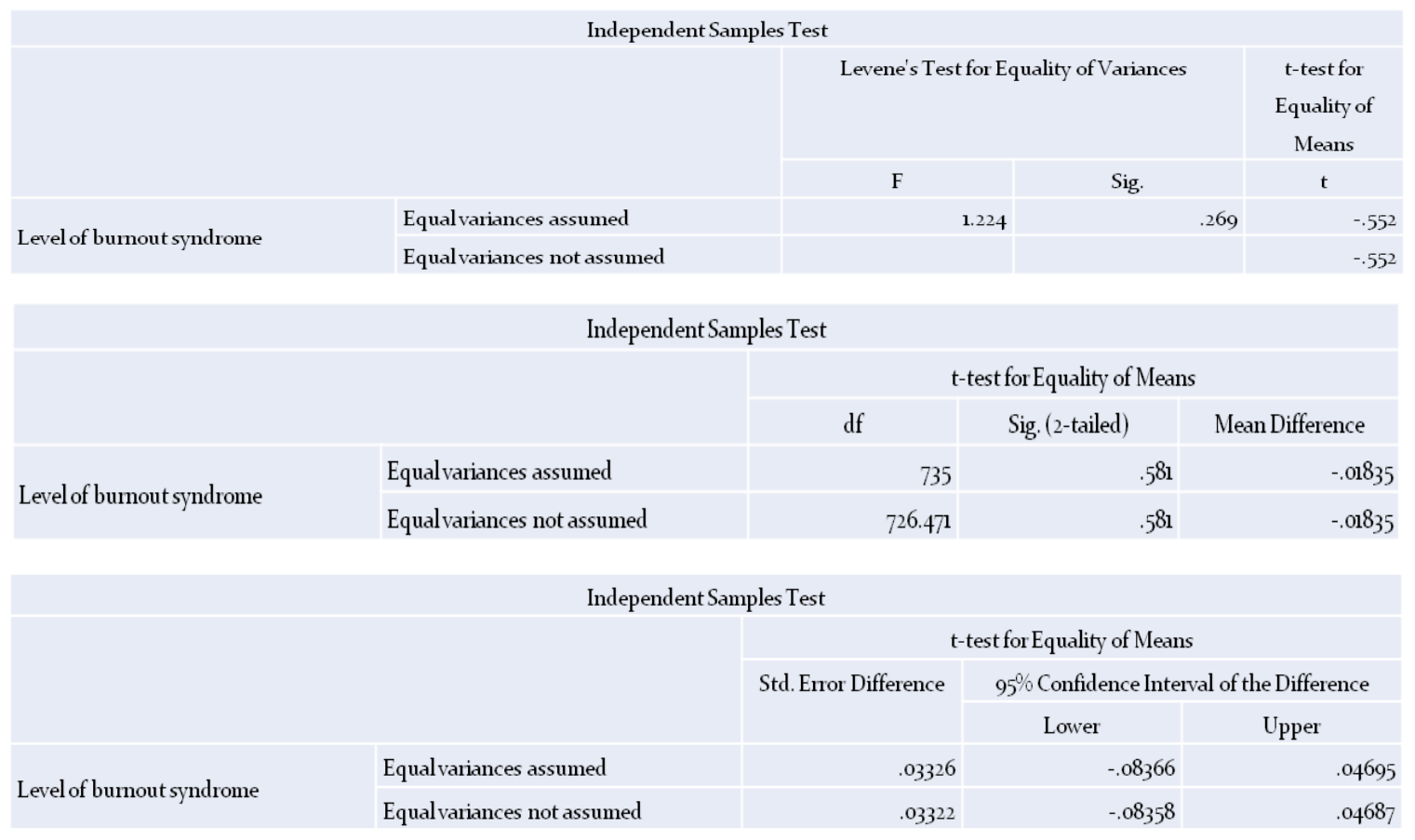

From the above table it can be noted that the association between nature of hospital (Govt. /Pvt.) and burnout syndrome are insignificant $(\mathrm{t}=-0.552 ; \mathrm{p}=0.581)$. Hence it can be pointed out that nature of the hospital, whether it is a Govt. /Pvt., is independent on the burnout of the physicians. 
Table IX: Association between department (Medical/Surgical) and burnout syndrome

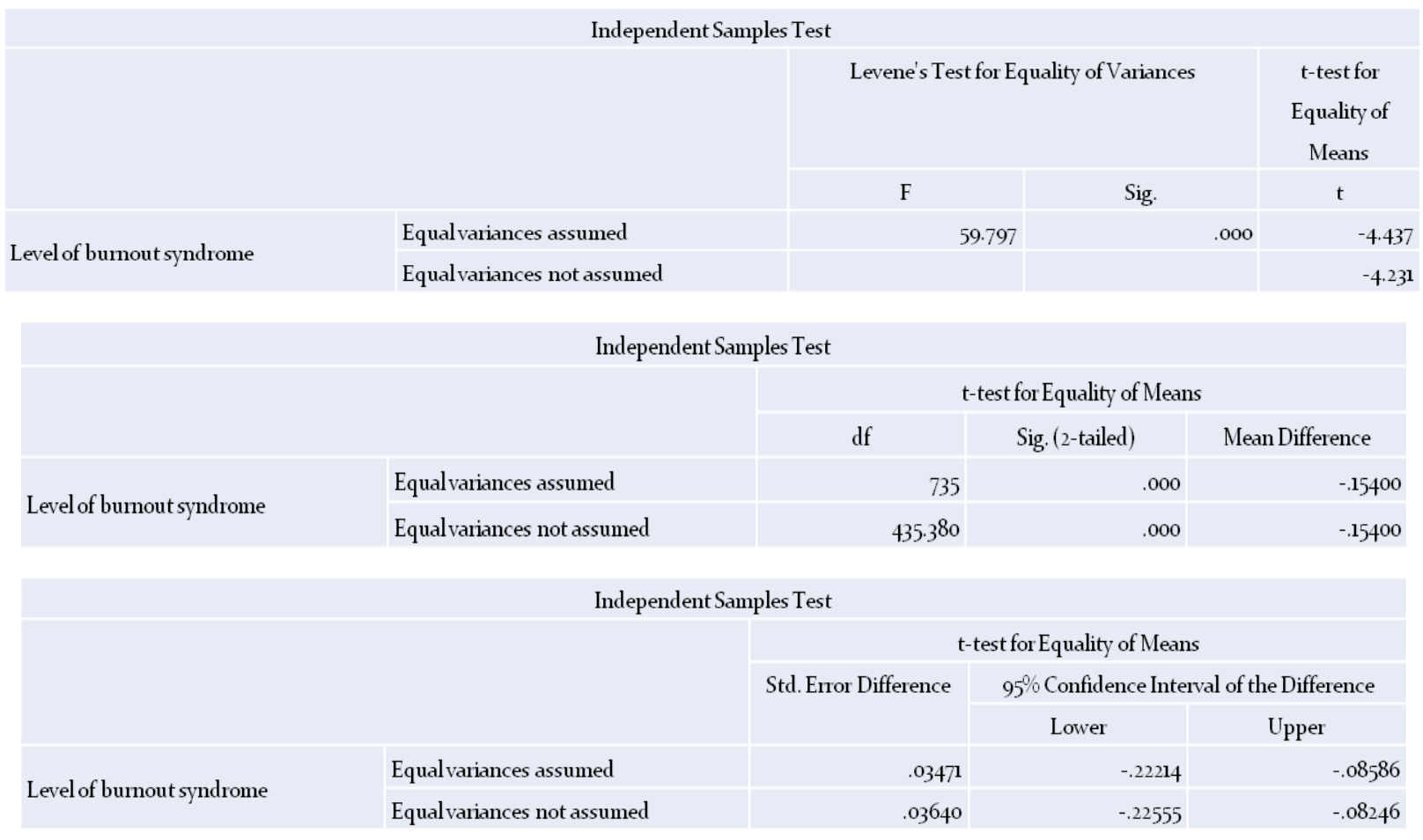

It is evident from the table that there is an association between the department where the physician works and their burnout $(\mathrm{t}=-0.44 ; \mathrm{p}=0.000)$. The comparison of mean score clearly states that the physicians are working at the surgical department $(\mathrm{M}=1.38 ; \mathrm{SD}=0.49)$ is higher in burnout than the physicians those who are working in the medical department $(\mathrm{M}=1.23 ; \mathrm{SD}=0.42)$.

Table X: Mean and Standard deviation of nature, of department (Medical/Surgical)and burnout syndrome Group Statistics

\begin{tabular}{|c|c|c|c|c|c|}
\hline & Department & $\mathrm{N}$ & Mean & Std. Deviation & Std. Error Mean \\
\hline \multirow{2}{*}{ Level of burnout syndrome } & Medical & 490 & 1.2306 & .42166 & .01905 \\
\hline & Surgical & 247 & 1.3846 & .48749 & .03102 \\
\hline
\end{tabular}

In the light of the above result, it can be argued that the physicians working in surgical department have high challenges and responsibility towards their patients. These can cause stress on their job and if stress persists for long times, then that may lead to the burnout. In a study by Tomasevic, Z; Jelic, S; Radosavljevic, D; \&Jezdic, S (2000) reported that the doctors working in oncology and radiology department were burned out due to their challenges and high responsibility in their works. Hence, it can be said that there is a significant difference between the departments of physicians' and their work may lead them to be burned out.

TABLE XI: Association between years of experience and burnout syndrome

ANOVA

Level of burnout syndrome

\begin{tabular}{|l|l|l|l|l|l|}
\hline & Sum of Squares & df & Mean Square & F & Sig. \\
\hline Between Groups & .949 & 4 & .237 & 1.171 & .322 \\
\hline Within Groups & 148.348 & 732 & .203 & & \\
\hline Total & 149.297 & 736 & & & \\
\hline
\end{tabular}

A non-significant result is observed between years of experience and burnout syndromes. So it can be said that, there is no association between years of experience and burnout of physicians. But contradiction to this, in a study from Abdullah, L and associates (2011), burnout syndrome were reversibly associated with years 
of experience. Of those with less than 10 yrs of experience were burned out. In the present study it denotes that physicians from Bangkok experiences burnout syndrome irrespective of their years of working experience.

\section{Discussion:}

Burnout is a general feeling of stress related exhaustion that develops, when a person experiences too much pressure and has very few sources satisfaction. The physical exhaustion is seen in signs of chronic fatigue, weakness and low energy. The mental exhaustion appears as irritability, anxiety, feelings of helplessness and hopelessness. The individual may develop disruption of working relationships, low job satisfaction, low organizational commitment so on. In this modern society, there is an invisible battle going on day by day between the physicians and their job stress. Physician burnout begins when he/she is not able to recharge his coping between the nights or days of steadiest overload of routine works. This pulls them down to physical and emotional exhaustion, depersonalization, and reduced sense of personal accomplishment.

Over the past few decades, many social scientists focused on their researches on burn out syndrome as a workplace health phenomenon. A considerable number of studies have assessed this condition in the health care profession. In the absence of previous investigation in Bangkok, the present investigation was designed to calculate the percentage of burnout syndrome among physicians working in various hospitals. The present study investigated that $28.2 \%$ of physicians had symptoms of burnout syndrome. This result is higher than with the other international studies have been reported.For instance, a Danish study of prevalence of burnout syndrome among general practitioners was reported that $25 \%$ of general practitioners were burned out (Brondt et. al, 2008). On the basis of the above information, only a 3\% difference is observed. This difference can possibly be explained by the variation of culture, or the nature of healthcare system in two specific countries.

The present investigation showed that there is a gender difference in burnout syndrome. According to the result, the female physicians suffer from more burnout than male physicians. From the previous researches it is well documented that there is a gender difference between health care workers such as physicians, nurses, and medical technicians in burnout syndrome, and the female gender is considered a determinant for developing the burnout syndrome. (Obrero.D, Gomez MJ, Meseguer, et.al. (2005). On the basis of the result, it can be stated that female physicians experience more stress from their works and the prolonged experience of the stress may lead them to burn out. Whereas, male physicians may manage their stress because of that they found themselves as low in burnout.

In the case of physicians working in surgical department has high challenges and responsibility towards their patients. These can cause stress on their job and if stress persists for long times, then that may lead to burnout. In a study by Tomasevic, Z; Jelic, S; Radosavljevic, D; \&Jezdic, S (2000) reported that the doctors working in oncology and radiology department were burned out due to their challenges and high responsibility in their works.

Other factors such as age, marital status, place of work, nature of hospitals, and years of experience were not found any significant difference with burnout syndrome. Hence it can be concluded that in those factors, all of the physicians were equally experiencing a burnout syndrome.

\section{Conclusion}

This type of investigation was never performed before in Bangkok thus the presented results are the first and, let us hope, just preliminary. It seems that stress is very well tolerated among physicians working in the surgery department. $28.2 \%$ of the physicians reported that they are burned-out, and this indicates only the minority of participants seems to be under the extreme stress. It is necessary to come up with more studies on burnout research. So the investigators expecting this would be a good stimulator for the future stress researchers. Another interesting factor is noted that among the physicians, female physicians are higher in burnout than males. So it is advised that female physicians should be trained to handle the stressful situations or should teach them effective coping methods to decrease their burnout.

At healthcare organizational level, some positive interventions should be adapted to the health care systems. These types of positive interventions will help the physicians working in the surgery department to reduce their stress and burnout. Decreased workload and social support from other staff will also be helpful in this matter. In this regard it should be also advisable to conduct more rigorous researches in this area to find out the relationship between in-depth factors of stress and burnout. 


\section{References}

[1] Abdulghafur, Y.(2011). Burnout syndrome among physicians working in primary healthcare centers in Kuwait. Alexandra Journal of Medicines, 47, 351-357.

[2] https://doi.org/10.1016/j.ajme.2011.08.004

[3] Abdulla, L., Al-Qahtani, D. M., \& Al-Kuwari, M.G. (2011) Prevalance and determinants of burnout syndrome among primary healthcare physicians in Qatar. South African Family Practice, 53:4, 380-383.

[4] https://doi.org/10.1080/20786204.2011.10874118

[5] Brondt, A., Sokolowski, I., Olesen, F., \& Vedsted, P. (2008). Continuing medical education and burnout syndrome among Danish GPs. Br.J GenPract. 58 (546): 15-29.

[6] https://doi.org/10.3399/bjgp08X263767

[7] Burisch, M. (2006). Das Burnout-Syndrome: Theorie der inneren Erschopfung [The Burnout-Syndrome: A Theory of inner Exhaustion]. Heidelberg: Springer Medizin Verlag

[8] Costa, F.O. et.al.(2012). Burnout Syndrome and associated factors among medical students: a cross -sectional study. Clinics vol. 67, no. 6, Sao Paulo.

[9] Embriaco, N., Papazian, L., Kentish-Barnes, N. et.al (2007). Burnout syndrome among critical care healthcare workers. CurrOpinCrit Care. 13(5) 482-8

[10] https://doi.org/10.1097/mcc.0b013e3282efd28a

[11] Farber, BA. (1998). Tailoring treatment strategies for different types of burnout. Paper presented at the annual convention of American Psychological Association, , San Franscisco California, August 14-18 Ed 106th, 424-517

[12] Hamad Medical Coperation. (2009). Annual health report 2009, Doha.

[13] Marcia Oliveira Staffa Tironi et.al. (2009) Professional Burnout Syndrome among intensive care physicians in Salvador, Barzil. Rev.Assoc.Med.Bras. Vol.55 no. 6 Sao Paulo

[14] Maslach, C., Jackson, S.E., \& Leiter, M.P. (1996). The Maslach Burnout Inventory Manual (3rd ｅd.). Palo Alto, CA: Consulting Psychologist Press.

[15] Melamed, S.,Shirom, A., Toker, S., \& Shapira, I. (2006). Burnout and risk of Type 2 diabetes: A perspective study of apparently healthy employed persons. Psychosomatic Medicine, 68, 863-869

[16] https://doi.org/10.1097/01.psy.0000242860.24009.f0

[17] Obrero.D, Gomez M.J, Meseguer, et.al. (2005). Prevalence of burnout syndrome among resident physicians in orthopedic surgery and traumatology departments in Spain. Bone Joint Surg Am, 8: 329-330.

[18] Ribeiro, V.F., et.al. (2014). Prevalence of burnout syndrome in clinical nurses at a hospital of excellence. Inernalt Archieves of Medicine; 7:22.

[19] https://doi.org/10.1186/1755-7682-7-22

[20] Selmanovic, S.,et.al. (2011). Stress at work and burnout syndrome in hospital doctors. Med Arch. 65(4):221-4.

[21] https://doi.org/10.5455/medarh.2011.65.221-224

[22] Shanafelt,T. D., et.al. (2012). Burnout and satisfaction with work-life balance among US physicians relative to general US population. Archives International Medicines, 172 (18): 1377-85.

[23] https://doi.org/10.1001/archinternmed.2012.3199

[24] Spiickard, A. J. R.,Gabbe, S. G., \& Christensen, JF. (2002). Mid career burnout in generalist and specialist physicians. JAMA, 288: 1447-1450

[25] https://doi.org/10.1001/jama.288.12.1447

[26] The Nation (2009) The healthcare service in Thailand A Report in the news paper "The nation".

[27] Thorsen, V. C., Tharp, A. L., \& Meguid, T. (2011). High rates of burnout among meternal health staff at a referral hospital in Malawi: A cross-sectional study. BMC Nursing, 10:9.

[28] https://doi.org/10.1186/1472-6955-10-9

[29] Tomasevic, Z., Jelic,S., Radosa vljevic, D., \& Jezdic, S. (2000). Burnout syndrome among medical staff in the institute for oncology and radiology of Serbia. Arch Oncol 8 Suppl. 1:5-6.

[30] Verdugo, A., et.al. (2013). Prevalence of Burnout syndrome in nursing staff of a third level hospital Boyaca, Colobia. Enfermeria Global, no. 29.

[31] Yousefy A. R, \& Ghassemi G. R, (2006) Job burnout in psychiatric and medical nurses in Isfahan, Islamic Republic of Iran. East Mediterr Helath J, 12 (5): 662-669 